\title{
The Mental Health of Australian University Students
}

\author{
Vivienne Browne \\ Senior Policy Analyst, Orygen \\ The National Centre of Excellence in Youth Mental Health \\ Jonathan Munro \\ Head of Counselling \& Psychological Support Services \\ Southern Cross University \\ Jeremy Cass \\ Manager \\ RMIT Counselling Service.
}

\begin{abstract}
Australian and international research suggests university students are experiencing heightened psychological distress, in part due to academic and financial pressures, isolation, loneliness and poor self-care. University years also often coincide with the critical transition period (between the ages of 17 and 25 years) when mental illness is most likely to onset.

While the Australian Government's higher education policies have driven increases in participation and equity, little attention has been given to supporting the 'mental wealth' of students and responding to experiences (and risk factors) of mental ill-health which can place them at risk of academic failure. Further, mental health and suicide prevention policies across all levels of government have focused on providing educational support within primary and secondary school settings and largely ignored the role of tertiary education. This is despite the significant numbers of Australian young people engaged in these settings.
\end{abstract}

There remains contention about the extent of the problem and whether the core business of higher education delivery includes supporting students' mental health and wellbeing. Regardless, universities across Australia have been independently developing policies and programs to respond to mental health issues presenting on campus. As such, national leadership and guidance is needed to: a) improve data collection on the prevalence of mental ill-health among university students; $b$ ) articulate the reasonable expectations of universities in responding to students' mental health issues; c) describe opportunities for partnership between universities and community mental health services; and d) promote evidence-based, appropriate and acceptable programs and interventions.

Keywords: mental health, university students, counselling services, policy, early intervention

\section{Introduction}

In May 2017, Orygen, The National Centre of Excellence in Youth Mental Health (Orygen), released the report Under the radar: The mental health of Australian university students (Orygen, 2017). The report aimed to:

a) Build an understanding of the prevalence of mental ill-health, impact and helpseeking behaviours among university students.

b) Identify evidence for effective interventions and good practice.

c) Highlight current gaps in policy, program and institution responses.

d) Recommend future directions for higher education and mental health policy makers, as well as sector leaders.

While the report focuses on issues for university students, the authors recognise that a number of 
universities are dual sector, in that they deliver both higher education and vocational education and training (VET).

In April 2016, the Australian and New Zealand Student Services Association (ANZSSA) Heads of Counselling Services, participated in a symposium hosted at RMIT in Melbourne, Australia. The organisers of this event provided Orygen with a valuable opportunity to present to, and consult, attendees. The common experiences of this group, who are at the coal face in delivering supports to students, contributed to the recommendation for national action on this issue.

\section{Prevalence}

The paucity of Australian research and data on Australian university students' mental health makes it difficult to accurately describe the extent of the issue. Among the general population of young people we know that one in four will have an experience of mental ill-health in any given year (Australian Bureau of Statistics, 2008) and that $75 \%$ of mental illness onsets before the age of 24 years (Kessler et al., 2005).

Along with findings from international research, suggesting higher prevalence of depression and anxiety among university cohorts compared to a broader population of 18-24 year olds (Eisenberg, Gollust, Golberstein, \& Hefner, 2007; Eisenberg, Hunt, \& Speer, 2013), a number of identified Australian-based studies reported high to very high levels of distress among university students (Larcombe, Finch, \& Sore, 2014; Leahy et al., 2010; Mulder \& Cashin, 2015; Stallman, 2010). However, many of these studies identified limitations regarding the size and diversity of the samples and in the reliance on self-report measures. Another paper analysing the results from three Australian national surveys conducted in 2007-2008 found tertiary students (including higher education and VET) were more likely to experience mild to moderate levels of psychological distress than non-students, although differences were not found for high distress (Cvetkovski, Reavley, \& Jorm, 2012).

In April 2017, an Australian survey on the mental health of tertiary students found $65 \%$ of respondents aged 16-25 years reported high or very high psychological distress while $35.4 \%$ had thoughts of self-harm or suicide (headspace \& National Union of Students, 2017). While an important survey, with over 3000 respondents, the sample was self-selected, suggesting a skew and bias within the data.

Aggregating counselling service client data has been difficult due to a lack of standardised screening/assessment tools and measures used and other opportunities to build our understanding are being missed. For example, the annual Student Experience survey of over 100,000 higher education students (QILT Social Research Centre, 2017), which already asks students about their experiences accessing support services, could be augmented to include a small sub-set of questions relating to experiences of mental health and wellbeing and the perceived factors which influence this.

In this 'data-thin' environment, Australian university counselling services provide a valuable source of information on the experiences of mental ill-health among students. Many service managers and staff have described an increase in mental health presentations which are, in some instances, complex and severe in nature (Orygen, 2017). Most counselling service managers across Australia and New Zealand have indicated that they do not have the capacity to respond to service demand. Emerging issues included urgent presentations, suicidality, eating disorders and levels of psychological distress (Andrews, 2016).

To further highlight the need for mental health supports on campus, a KPMG evaluation of the 
Disability Support Programme found more students were presenting to disability services with mental ill-health and staff were unsure how to support these students. As a result the bulk of funding continued to support the needs of students with physical disabilities (KPMG, 2015).

There are most likely a myriad of factors influencing this increased demand for university mental health supports and services. Due to participation targets in higher education policy following the Bradley Review recommendations (Bradley, 2008), there is now a significant population of Australian university students, 1.4 million in 2015 (Department of Education, 2016). Driven through a commendable equity agenda in higher education, an increasing number of these students are the first in their family to attend university, from low socioeconomic backgrounds (SES), rural and regional areas and have an identified disability (including mental ill-health) (Universities Australia, 2017).

Students are also likely to have higher levels of mental health literacy following exposure to awareness campaigns and prevention/early intervention programs in secondary and even primary school. More than ever, young people are equipped with the knowledge and skills to identify their own mental health issues, or mental health issues in their peers, and seek support.

\section{Risk factors}

A number of specific risk factors contribute to poor mental health among university students. Academic pressures and performance expectations are significant issues facing students (Deasy, Coughlan, Pironom, Jourdan, \& Mannix-McNamara, 2014; Kruisselbrink Flatt, 2013). Many students are cognisant of the 'rising bar' for qualifications in Australia (VicHealth \& CSRISO, 2015) and are extending study into post-graduate qualifications, while enhancing their resume, and competitive edge, through a range of extracurricular activities.

Financial pressures and low SES are also associated with higher levels of psychological distress and mental disorders among university students (Cvetkovski et al., 2012; Eisenberg et al., 2013; Stallman, 2010). A Universities Australia (2013) report found that among students, two-thirds were worried about their financial situation and $17 \%$ reported regularly going without necessities (including food) because they were unable to afford them. Many students combine work and study (sometimes full-time loads), impacting on their quality of life, their social relationships and other risk factors for mental ill-health including lifestyle - such as poor diet and alcohol use (Kruisselbrink Flatt, 2013) and insufficient sleep (Hershner \& Chervin, 2014; Thomee, Harenstam, \& Hagberg, 2012). While struggling to 'make ends meet' during their time at university, many students are also accruing significant future debt. In 2016-17 the estimated average student HELP debt was $\$ 19,100$, taking approximately 8.8 years to repay (Department of Education and Training, 2016).

Rural and regional (Mulder \& Cashin, 2015), Aboriginal and Torres Strait Islander (Toombs \& Gorman, 2011) and international students (Forbes-Mewett \& Sawyer, 2011) appear to be at increased risk of experiencing poor mental health while at university. For these young people, the stressors of university life can be compounded by relocation from families, friendship and support networks, cultural connections and traditional lands. Analysis of data from the 2013 Student Experience Survey found low SES, rural/regional and Aboriginal and Torres Strait Islander students were more likely to cite health and stress reasons for considering an early course exit, compared to high-socioeconomic, metro and non-Aboriginal and Torres Strait Islander students for whom the main reasons for considering an early exit included: boredom, change of direction and career opportunities (Edwards \& McMillan, 2015).

Meanwhile, negative and harmful experiences on campus can further impact mental health 
outcomes and the need for support services. On 2 August 2017 the Australian Human Rights Commission (AHRC) released Change the Course: National Report on Sexual Assault and Harassment at Australian Universities. This report presented the results of the largest ever national survey of Australian university students on sexual harassment and sexual assault. These results included that one in five survey respondents had experienced sexual harassment at university in 2016 and $1.6 \%$ had experienced sexual assault in a 'university setting' in 2015 or 2016 (AHRC, 2017).

\section{Help-seeking}

Australian research suggests that among university student populations more than half are unlikely to seek help for mental health issues (Stallman \& Shochet, 2009; Wynaden, Wichmann, \& Murray, 2013). Students report not wanting to be seen as less capable than their peers and/or not knowing where to seek help. Personal stigma is particularly evidenced among young men, students from culturally and linguistically diverse backgrounds, international students and students from low SES backgrounds (Eisenberg, Downs, Golberstein, \& Zivin, 2009).

Young people identify that their preferred sources for seeking help are family and friends (Mission Australia, 2014). Peer-based programs have flourished on university and college campuses, both in Australia and internationally including batyr@uni (Australia), jack.org (Canada) and Student Minds (UK). On some campuses, peer programs appear to have developed through student action and/or a growing awareness that students themselves can be accessible and acceptable mental health advocates and facilitators of help-seeking to appropriate, evidence-based care.

\section{Impact}

'Mental wealth' is a term that has gained traction in mental health advocacy and policy discussions (McGorry, 2017). It this context it refers to the social and economic productivity which can be achieved from supporting a mentally healthy population and providing effective and early treatment of mental ill-health.

Under the radar highlights the potentially significant costs of not fostering mental wealth within the university environment. The 2016 Student Experience Survey found that among students who were considering exiting their course, $41 \%$ cited health and stress reasons (QILT Social Research Centre, 2017). Early course exiting has an obvious individual impact. This includes future difficulties/delays entering the workforce and exacerbated experiences of mental ill-health through a perception of failure, damaging self-esteem and self-worth.

The impact on university staff and services is already evident through the demand for campus counselling and disability services. Teaching staff in tertiary education have also reported difficulties in determining appropriate responses when mental ill-health impacts a student's capacity to complete necessary course requirements, including examinations and work-placements (Venville, Street, \& Fossey, 2014).

Meanwhile, the Australian Government provides a significant amount of funding to higher education providers, subsidising tuition costs, providing scholarships and funding other programs, such as the Higher Education Participation and Partnerships Program to support participation among Australians from low SES backgrounds. It is important that these investments not only increase access to higher education but support attainment outcomes for students and the broader community.

In Australia, an economic cost-benefit study of investing in university student mental health has not been undertaken. However, a study in the United States found a social return of $\$ 6.49$ on every $\$ 1$ 
spent by the government on prevention and early intervention in college student mental health. This was based on mitigating against course incompletion, loss of future workforce potential and downstream mental health system costs. The study found that for community college students (where we can draw the closest parallels with Australian TAFEs) the net benefits were estimated to be even higher at $\$ 11.39$ for each dollar invested (Ashwood et al., 2015).

\section{Evidence base for programs and interventions}

There are many universities across Australia taking significant steps to develop programs and services which respond to mental health issues on campus. These have included: awareness raising events and programs, mental health and mindfulness training, comprehensive online portals (such as The Desk) and peer-based support programs.

There is good evidence for the improvement of knowledge and self-perceived capacity to respond among university staff and students trained in mental health literacy programs such as Mental Health First Aid (B. Davies, Beever, \& Glazebrook, 2016; Lipson, Speer, Brunwasser, Hahn, \& Eisenberg, 2014). However, as Lipson et al. (2014) found, effects are not apparent for the translation of these improvements into help-seeking behaviours or mental health service utilisation among students.

There is also evidence for the effectiveness of brief interventions (three to four sessions), as delivered by counselling and student support services, particularly among students who complete the course of therapy. Improvements in educational outcomes among students who access university counselling services are particularly evident (Connell, Barkham, \& Mellor-Clark, 2008; Murray, McKenzie, Murray, \& Richelieu, 2016). In the United States, self-report data from students on the educational and academic impact of accessing counselling services found $71 \%$ responded positively (Reetz, Krylowicz, Bershad, Lawrence, \& Mistler, 2015).

There is some evidence for awareness and information programs. Studies have found positive shifts in attitudes from brief classroom-based education programs delivered to students and staff which raise awareness of mental health issues and services (Sharp, Hargrove, Johnson, \& Deal, 2006) and in behavioural change from the delivery of strengths-based resilience building seminars (Stallman, 2011). Awareness raising programs may be more effective when delivered in conjunction with other interventions, such as training. One study found that a multifaceted intervention, including emails, posters, events and training improved willingness to seek help among students and staff (Reavley, McCann, Cvetkovski, \& Jorm, 2014).

Given peer-based programs are an emerging field of practice in youth mental health it is not surprising that limited evidence exists to date regarding their effectiveness in university settings. The potential for these approaches to provide accessible and acceptable mental health supports for university students is significant. However, as found from research into a peer-based support program of university students in the United Kingdom, care needs to be taken to ensure the mental health of peers is not compromised through their task of supporting others (Student Minds, 2016).

\section{Role of technology}

Technology has an increasingly important role in mental health service provision across Australia. These platforms respond to information and service preferences (particularly for young people) and address the gaps in care that exist outside normal business hours and in rural and regional areas. The Australian Government is soon to release a digital gateway to mental health care and provides people living in rural and remote areas with Medicare rebates for online videoconferencing consultations with psychologists (Hunt, 2017a). Further, a number of highly regarded national 
mental health online/TeleWeb services already exist including: Lifeline, eheadspace, beyondblue and ReachOut.

For university counselling services, technology can provide students with an alternative avenue to help-seeking (particularly students less likely to engage directly through conversational means). It can also facilitate outreach through accessible and available supports which 'match students' schedules and not just conform to university business hours' (Veness, 2016, p. 30). Should students find it difficult to access counselling services for support, the provision of evidence-based technological platforms can mitigate against the risk of them using less effective sources of support, such as peer advice on social media, or not engaging at all (Inglis \& Cathcart, 2016). A number of regional universities have implemented an out-of-hours support service in recent years including: Southern Cross University in 2013, Charles Darwin University in 2015 and Swinburne and Griffith Universities in 2017.

There is evidence for the use of technology-based interventions among university students, with some studies finding efficacy in targeting certain mental health conditions such as depression, anxiety and stress (E. B. Davies, Morriss, \& Glazebrook, 2014; Farrer et al., 2013). Therapist assisted or supported online interventions have also shown efficacy for the general population (Wagner, Horn, \& Maercker, 2014) and for university students, particularly when incorporated into the delivery of other online programs (Sharry, Davidson, McLoughlin, \& Doherty, 2013).

\section{Where are the gaps?}

\section{Policy}

At present there is no high level government direction provided to Australian universities regarding their role: a) broadly, in promoting and enhancing good mental health and wellbeing across the institution and b) specifically, in supporting of students who may be experiencing distress or mental health difficulties.

Under the radar also identifies the failure of mental health policies and programs to incorporate tertiary education settings within their focus. Orygen reviewed state, territory and federal government mental health and suicide prevention policies and found very few mentioned tertiary education as settings for action or program delivery. The Australian Government recently announced a \$52.6 million National Support for Child and Youth Mental Health Program (Hunt, $2017 \mathrm{~b}$ ) to be delivered in early childhood centres, primary and secondary schools. Again tertiary education settings were not included in the program's remit. This is a significant gap in the provision of prevention and early intervention at a point of life where experiences of mental illhealth are common and the risk of onset of mental illness peaks.

Data drives policy change and the lack of regularly collected and monitored data on the experiences of mental ill-health among university students may be contributing to the minimal recognition, investment and program activity delivered by governments. What isn't measured often doesn't count and at present it is still possible for politicians, policy makers and university leaders to question the extent of the issue and whether it is one that really requires national attention.

\section{National guidance for whole-of-institution responses}

As identified by Veness (2016) in his report The wicked problem of university student mental health, very few universities in Australia have developed a whole-of-institution policy response to mental health and wellbeing. While an overarching set of guidelines for supporting tertiary students' mental health and wellbeing was released in 2011 (University of Melbourne \& Orygen Youth Health Research Centre, 2011), there is a need to develop more comprehensive and detailed 
guidance for universities. This should identify action across the institution and be linked into existing policy and legislative frameworks.

In the United Kingdom, the peak body, Universities UK, has led this approach, initially through the Mental Wellbeing in Higher Education Working Group. Strong support from the peak body provides clear leadership and commitment from university Vice-Chancellors. This sets the 'tone from the top' for action across all areas of the institution as recommended by Veness (2016). One institute that has recently responded proactively to this recommendation has been RMIT University. RMIT have adopted the Framework for Enhancing Student Wellbeing (developed through a partnership between Melbourne University, Queensland University of Technology and Latrobe University) as a whole-of-institution policy response. RMIT has also appointed a Project Manager, Student Mental Wellbeing Initiatives, to roll-out this framework over the next three years.

There are international examples of national frameworks and guidance which can be leveraged. These include the Student mental wellbeing in higher education: Good Practice Guide (Universities UK \& Mental Wellbeing in Higher Education Group, 2015), as well as frameworks developed in Canada (CACUSS and CMHA, 2013) and the United States (The Jed Foundation and Education Development Center Inc., 2011). However, it is important that this guidance is translated into an Australian context and recognises the role of the Australian community mental health system.

\section{Service provision on and off campus}

Regardless of opinion on whether the role of universities should extend to mental health care provision, they do already provide support services including counselling, disability support and access to medical practitioners (specifically to provide brief interventions to support the attainment of educational outcomes).

As described earlier in this paper, there are significant concerns about the current capacity of university counselling services to meet demand. The International Association of Counseling Services Standards for University and College Counseling Services advise one counsellor for every 1000-1500 students. However, a 2013 benchmarking survey of Australian university counselling services found that, in the majority of institutions, the ratio was one counsellor to every 3000-5000 students (Andrews, 2016). Long wait periods for counselling appointments were also key concerns raised in submissions to the AHRC's National University Student Survey on Sexual Assault and Sexual Harassment. The Commission's report recommended universities conduct an audit of the average length of time students are required to wait for non-urgent counselling appointments, as well as the number of crisis requests, and increase resources where shortfalls were identified as a matter of urgency (AHRC, 2017).

There are also instances when the mental health care needs are of an acuity beyond the university health service's remit, resources and expertise. However, a number of counselling service managers consulted for Under the radar identified that there was a perception in the community that counselling services could provide treatment for students experiencing complex and severe mental health issues and even suicide risk. Stronger linkages with community mental health services appear to be needed. This includes a greater 'reach-in' by these services into universities to increase service awareness, promote access pathways and ensure timely and seamless referrals out of counselling services. Some universities have sought assistance from the local health district's mental health service in the form of a Memorandum of Understanding (MOU) to formalise the collaborative relationship between the services. This agreement recognises that both services play a complementary role in the provision of care and support to students who experience mental health issues and defines the continued commitment by both services to work together to achieve agreed joint outcomes. 


\section{Key Recommendations}

Under the radar recommends a number of areas for future action.

1. Policy responses: The Australian Government's higher education policy agenda must recognise that to produce a highly skilled and innovative future workforce, the core business of higher education delivery needs to include supporting the mental wealth of students. Further, mental health policies need to identify universities as settings to deliver mental health and suicide prevention programs. There is a particular opportunity for existing government-funded school education programs to be extended and provide mental health training and resources to frequent contact university staff (such as tutors and administration staff) as well as students. Meanwhile, all Australian universities should make a concerted effort to develop an institution-wide mental health strategy and implementation plan.

2. Measure it so it counts: There is a need to establish a baseline data set on university student mental health from which to benchmark and monitor the impact of future policy and program responses. Existing survey instruments, such as the Student Experience Survey in higher education, could be augmented to include questions regarding the experiences and influences of mental health and wellbeing, as well as help-seeking behaviours and experiences. There are also opportunities to aggregate counselling service data to gain a better understanding of the presentations of mental illhealth among students seeking support from these services. This would require national coordination to standardise screening and assessment tools used within these services.

3. Leadership and national coordination: Both mental health and higher education sector drivers are needed to lead and coordinate a response to this issue in Australia. Under the radar recommends that Universities Australia and a national mental health organisation partner, such as Orygen, work together to develop a guidance, training and monitoring mechanism of university responses to student mental health. Bringing together a steering group of key stakeholders, including Vice-Chancellors, mental health sector leaders and students, to drive this process would be an effective initial step.

4. Prioritise partnerships between mental health and higher education service delivery: The report recommends creating interdepartmental mechanisms within government to bring together higher education and mental health portfolios. There are also opportunities to develop partnerships at a regional level by involving universities in the service planning, coordination, research and evaluation activities of the 31 Primary Health Networks, the commissioners of primary youth mental health care in Australia. As is occurring in the United Kingdom, consideration could also be given to developing guidance for co-commissioning universities and local mental health services to provide coordinated and seamless student mental health supports.

5. Tap into technology: Online supports and interventions are acceptable and effective for university student populations. They also respond to the changing delivery of higher education which is increasingly provided through distance education. Under the radar recommends that future evidence-based online mental health portals developed or funded by the government are promoted and easily accessed within existing university online student interfaces. It also recommends further research and development of online platforms tailored to the needs, helpseeking preferences and schedules of university students.

6. Respond to heightened risk in students: The equity agenda for higher education participation is commendable. However, there remains a need to invest in and further develop supports and programs within universities to support at-risk students achieve academic outcomes. Particular attention is required to meet the needs of: international students, Aboriginal and Torres Strait 
Islander students and those from low SES backgrounds or rural areas. Counselling services also need to be resourced at levels which meet the demand and complexity of presentations.

7. Harness the capital within: Universities are a rich environment of expertise and skills in research, education and student advocacy. They are therefore ideal settings in which to develop and trial new and innovative approaches to university student mental health. This work and knowledge translation must be incentivised, both internally within the institution and through research funding provided through the National Health and Medical Research Council and/or the Australian Research Council.

\section{Conclusion}

University can, and should, be an enriching experience. For many younger students it forms part of an important transition into autonomy and independence. Yet a considerable number of students are experiencing psychological distress and mental ill-health during their studies. These experiences, if not responded to effectively, have the potential to derail students from their pathway towards productive careers and future good mental health and wellbeing. At present the mental health issues of university students are flying under the radar of policy attention and leadership in both higher education and mental health portfolios. Orygen believes there are a number of opportunities to address this within universities supported by: a) a national leadership and an approach to improving data collection and monitoring; b) building and disseminating the evidence base for effective interventions; and c) providing overarching guidance and frameworks. 


\section{References}

Andrews, A. (2016). ANZSSA Heads of Counselling Services Benchmarking Survey 2013 Summary Report. Journal of the Australian and New Zealand Student Services Association, 47, 96-105.

Ashwood, J., Stein, B., Briscombe, B., Sontag-Padilla, L., Woodbridge, M., May, E.,. .. Burnam, M. (2015). Payoffs for California college students and taxpayers from investing in student mental health. California: RAND Corporation.

Australian Bureau of Statistics. (2008). 2007 National survey of mental health and wellbeing: Summary of results (No: 4326.0) Retrieve from http://www.abs.gov.au/ausstats/abs@.nsf/mf/4326.0

AHRC. (2017). Change the course: National report on sexual assault and sexual harassment at Australian universities. Sydney, NSW: Australian Human Rights Commission.

Bradley, D. (2008). Review of Australian higher education. Final report. Canberra: Australian Government.

CACUSS and CMHA. (2013). Post-secondary student mental health: Guide to a systemic approach. Vancouver, BC: Canadian Association of College \& University Student Services and Canadian Mental Health Association.

Connell, J., Barkham, M., \& Mellor-Clark, J. (2008). The effectiveness of UK student counselling services: an analysis using the CORE System. British Journal of Guidance \& Counselling, 36(1), 1-18. doi: $10.1080 / 03069880701715655$

Cvetkovski, S., Reavley, N. J., \& Jorm, A. F. (2012). The prevalence and correlates of psychological distress in Australian tertiary students compared to their community peers. Australian \& New Zealand Journal of Psychiatry, 46(5), 457-467. doi: 10.1177/0004867411435290

Davies, B., Beever, E., \& Glazebrook, C. (2016). The mental health first aid eLearning course for medical students: a pilot evaluation study. European Health Psychologist, $18(\mathrm{~S}), 861$.

Davies, E. B., Morriss, R., \& Glazebrook, C. (2014). Computer-delivered and web-based interventions to improve depression, anxiety, and psychological well-being of university students: a systematic review and metaanalysis. Journal of Medical Internet Research, 16(5), e130. doi: 10.2196/jmir.3142

Deasy, C., Coughlan, B., Pironom, J., Jourdan, D., \& Mannix-McNamara, P. (2014). Psychological Distress and Coping amongst Higher Education Students: A Mixed Method Enquiry. PLoS One, 9(12), e115193. doi: 10.1371/journal.pone.0115193

Department of Education. (2016). 2015 Higher education statistics. Retrieved from https://docs.education.gov.au/system/files/doc/other/2015_infographic_0.pdf

Department of Education and Training. (2016). Portfolio budget statements 2016-17: Budget related paper no. 1.5 Education and Training Portfolio: Commonwealth of Australia.

Edwards, D., \& McMillan, J. (2015). Completing university in a growing sector: Is equity an issue? Melbourne: Australian Council for Educational Research.

Eisenberg, D., Downs, M. F., Golberstein, E., \& Zivin, K. (2009). Stigma and help seeking for mental health among college students. Medical Care Research and Review, 66(5), 522-541. doi: 10.1177/1077558709335173

Eisenberg, D., Gollust, S. E., Golberstein, E., \& Hefner, J. L. (2007). Prevalence and correlates of depression, anxiety, and suicidality among university students. American Journal of Orthopsychiatry, 77(4), 534-542. doi: 10.1037/0002-9432.77.4.534

Eisenberg, D., Hunt, J., \& Speer, N. (2013). Mental health in American colleges and universities: variation across student subgroups and across campuses. The Journal of Nervous and Mental Disease, 201(1), 60-67. doi: 10.1097/NMD.0b013e31827ab077

Farrer, L., Gulliver, A., Chan, J. K., Batterham, P. J., Reynolds, J., Calear, A.,. .. Griffiths, K. M. (2013). Technologybased interventions for mental health in tertiary students: Systematic review. Journal of Medical Internet Research, 15(5), e101. doi: 10.2196/jmir.2639

Forbes-Mewett, H., \& Sawyer, A.M. (2011). Mental Health Issues amongst International Students in Australia: Perspectives from Professionals at the Coal-face. The Australian Sociological Association Conference Local Lives/Global Networks. content/uploads/2011/11/Mental-Health-Issues-among-International-Students-in-Australia.pdf

headspace, \& National Union of Students. (2017). National tertiary student wellbeing survey 2016. Retrieved from https://headspace.org.au/assets/Uploads/headspace-NUS-Publication-Digital.pdf 
Hershner, S. D., \& Chervin, R. D. (2014). Causes and consequences of sleepiness among college students. Nature and Science of Sleep, 6, 73-84. doi: 10.2147/NSS.S62907

Hunt, G. (2017a). Budget to deliver telehealth boost for rural psychological services [Press Release]. Retrieved from http://www.health.gov.au/internet/ministers/publishing.nsf/Content/7E6354A2A9BA7E21CA2581070013F4F 2/\$File/GH035.pdf

Hunt, G. (2017b). \$73 million to support the mental health of Australian children. [Press Release] Retrieved from http://www.health.gov.au/internet/ministers/publishing.nsf/Content/699F3C3324F4C0C5CA25813900063E3A /\$File/GH057.pdf

Inglis, B., \& Cathcart, K. (2016). Navigating the shift toward online service Delivery: A counselling service perspective. ANZSSA 2016 Conference. Retrieved from https://anzssa.com/Public/Public/ANZSSA2016Conference/ANZSSA_2016_Conference_Proceedings.aspx

International Association of Counseling Services: Standards for university and college counseling services. (2011). Journal of College Student Psychotherapy, 25(2), 163-183. doi: 10.1080/87568225.2011.556961

Kessler, R. C., Berglund, P., Demler, O., Jin, R., Merikangas, K. R., \& Walters, E. E. (2005). Lifetime prevalence and age-of-onset distributions of DSM-IV disorders in the National Comorbidity Survey Replication. Archieves of General Psychiatry, 62(6), 593-602. doi: 10.1001/archpsyc.62.6.593

KPMG. (2015). Department of education and training evaluation of disability support program: Final report: KPMG. Retrieved from https://docs.education.gov.au/system/files/doc/other/dsp_evaluation_report_final_june_2015.pdf

Kruisselbrink Flatt, A. (2013). A Suffering Generation: Six factors contributing to the mental health crisis in North American higher education. College Quarterly, 16(1).

Larcombe, W., Finch, S., \& Sore, R. (2014). Who's Distressed? Not Only Law Students: Psychological Distress Levels in University Students Across Diverse Fields of Study Sydney Law Review, 37, 243-273.

Leahy, C. M., Peterson, R. F., Wilson, I. G., Newbury, J. W., Tonkin, A. L., \& Turnbull, D. (2010). Distress levels and self-reported treatment rates for medicine, law, psychology and mechanical engineering tertiary students: cross-sectional study. Australian \& New Zealand Journal of Psychiatry, 44(7), 608-615. doi: 10.3109/00048671003649052

Lipson, S. K., Speer, N., Brunwasser, S., Hahn, E., \& Eisenberg, D. (2014). Gatekeeper training and access to mental health care at universities and colleges. Journal of Adolescent Health, 55(5), 612-619. doi: 10.1016/j.jadohealth.2014.05.009

McGorry, P. (2017). Youth mental health and mental wealth: reaping the rewards. Australasian Psychiatry, 25(2), 101103. doi: $10.1177 / 1039856217694768$

Mission Australia. (2014). Young people's mental health over the years: Youth survey 2012-14. Sydney: Mission Australia and Black Dog Institute.

Mulder, A. M., \& Cashin, A. (2015). Health and wellbeing in students with very high psychological distress from a regional Australian university. Advances in Mental Health, 13(1), 72-83. doi: 10.1080/18374905.2015.1035618

Murray, A. L., McKenzie, K., Murray, K. R., \& Richelieu, M. (2016). An analysis of the effectiveness of university counselling services. British Journal of Guidance \& Counselling, 44(1), 130-139. doi: 10.1080/03069885.2015.1043621

Orygen (2017) Under the radar: The mental health of Australian university students. Melbourne: Orygen, The National Centre of Excellence in Youth Mental Health.

QILT Social Research Centre. (2017). 2016 student experience survey national report. Retrieved from https://www.qilt.edu.au/docs/default-source/gos-reports/2017/2016-ses-national-reportfinal.pdf?sfvrsn=14e0e33c_5

Reavley, N. J., McCann, T. V., Cvetkovski, S., \& Jorm, A. F. (2014). A multifaceted intervention to improve mental health literacy in students of a multicampus university: a cluster randomised trial. Social Psychiatry and Psychiatr Epidemiology, 49(10), 1655-1666. doi: 10.1007/s00127-014-0880-6

Reetz, D., Krylowicz, B., Bershad, C., Lawrence, J., \& Mistler, B. (2015). The Association for University and College Counseling Center Directors annual survey: Reporting period: September 1, 2014 through August 31, 2015: The Association for University and College Counseling Center Directors. 
Sharp, W., Hargrove, D. S., Johnson, L., \& Deal, W. P. (2006). Mental Health Education: An Evaluation of a Classroom Based Strategy to Modify Help Seeking for Mental Health Problems. Journal of College Student Development, 47(4), 419-438.

Sharry, J., Davidson, R., McLoughlin, O., \& Doherty, G. (2013). A Service-Based Evaluation of a Therapist-Supported Online Cognitive Behavioral Therapy Program for Depression. Journal of Medical Internet Research, 15(6) e121. doi: 10.2196/jmir.2248

Stallman, H. (2010). Psychological distress in university students: A comparison with general population data. Australian Psychologist, 45(4), 249-257. doi: 10.1080/00050067.2010.482109

Stallman, H., \& Shochet, I. (2009). Prevalence of mental health problems in Australian university health services. Australain Psychologist, 44(2), 122-127.

Stallman, H. (2011). Embedding resilience within the tertiary curriculum: a feasibility study. Higher Education Research \& Development, 30(2), 121-133. doi: 10.1080/07294360.2010.509763

Student Minds. (2016). Looking after a mate: A research report for student minds. Oxford, UK: Student Minds.

The Jed Foundation and Education Development Center Inc. (2011). Guide to campus mental health action planning. New York: The Jed Foundation and Education Development Center Inc.

Thomee, S., Harenstam, A., \& Hagberg, M. (2012). Computer use and stress, sleep disturbances, and symptoms of depression among young adults--a prospective cohort study. BMC Psychiatry, 12, 176. doi: 10.1186/1471244x-12-176

Toombs, M., \& Gorman, D. (2011). Mental health and indigenous university students. Aboriginal and Islander Health Worker Journal, 35(4), 22-24.

Universities Australia. (2013). University Student Finances in 2012. Canberra: Universities Australia and Centre for the Study for Higher Education, The University of Melbourne.

Universities Australia. (2017). Data Snapshot 2017. Retrieved from https://www.universitiesaustralia.edu.au/australiasuniversities/key-facts-and-data\#.WayePLIjGUk

Universities UK, \& Mental Wellbeing in Higher Education Group. (2015). Student mental wellbeing in higher education. Good practice guide. London: Universities UK.

University of Melbourne, \& Orygen Youth Health Research Centre. (2011). Guidelines for tertiary education institutions to facilitate improved educational outcomes for students with a mental illness. Melbourne: University of Melbourne and Orygen Youth Health Research Centre.

Veness, B. (2016). The wicked problem of university student mental health. Sydney: Winston Churchill Memorial Trust.

Venville, A., Street, A. F., \& Fossey, E. (2014). Good intentions: teaching and specialist support staff perspectives of student disclosure of mental health issues in post-secondary education. International Journal of Inclusive Education, 18(11), 1172-1188. doi: 10.1080/13603116.2014.881568

VicHealth \& CSRISO. (2015). Bright futures: Megatrends impacting the mental wellbeing of young Victorians over the coming 20 years. Melbourne: Victorian Health Promotion Foundation.

Wagner, B., Horn, A., \& Maercker, A. (2014). Internet-based versus face-to-face cognitive-behavioral intervention for depression: A randomized controlled non-inferiority trial. Journal of Affective Disorders, 152-154, $113-121$.

Wynaden, D., Wichmann, H., \& Murray, S. (2013). A synopsis of the mental health concerns of university students: results of a text-based online survey from one Australian university. Higher Education Research \& Development, 32(5), 846-860. doi: 10.1080/07294360.2013.777032

The authors may be contacted via

vivienne.browne@ orygen.org.au 